\title{
Postharvest Losses in the Wheat Logistics Chain: A Brazilian Case Study
}

Daniela Bacchi Bartholomeu, Fernando Vinícius da Rocha, Thiago Guilherme Péra and José Vicente Caixeta-Filho

Research and Extension Group in Agroindustrial Logistics (ESALQ-LOG), University of Sao Paulo (USP), Piracicaba, São Paulo, Postal Code 13418-900, Brazil

\begin{abstract}
This paper highlighted the losses occurring along the wheat supply chain in Rio Grande do Sul (RS), Brazil, which accounts for almost half of the domestic wheat production. Based on a field research, a questionnaire was applied to representative agents in the market. Then the wheat supply chain in the state of RS was characterized and loss rates in each stage of that chain were quantified. Typically, losses during transportation in the domestic market account for about $11.8 \%$ of the total amount of wheat grain that leaves the farms. Losses during harvest and storage in cooperatives, which account for $93.2 \%$ of total losses, stand out in this context. Transportation operations account for $6.8 \%$ of total losses in the analyzed flow. Based on the results obtained in this study, strategies are suggested to reduce food losses in different links of the logistics chain, such as to evidence and quantify the wheat losses, to manage losses and set reduction targets and to give attention to transportation service levels.
\end{abstract}

Key words: Postharvest losses, wheat, supply chain, food security.

\section{Introduction}

Studies suggest that global food production must increase by about $70 \%$ to make it possible to feed the world population in 2050. However, the limited resources, such as arable land, water and energy, may impose serious difficulties for food production to respond to this need. Increasing agricultural productivity has been a frequent quest to meet the growing demand for food and ensure food security.

In this context, it is important to find strategies to increase the food availability. Since it is estimated that $25 \%$ calories are not consumed by humans due to losses that occur at different stages of the food production chain, reducing losses is seen as a win-win strategy. Besides contributing to food security, it also reduces the pressure on the environment, especially on ecosystems, climate and water sources.

According to data from Lipinski et al. [1], about 24\% of these losses occur during production, 24\% during

Corresponding author: Daniela Bacchi Bartholomeu, Ph.D., research field: agroindustrial logistics. handling and storage, 4\% during processing and packaging, $12 \%$ during marketing and distribution, and $35 \%$ during consumption.

However, estimates of food losses differ widely among studies that have been carried out already, including at international level. Moreover, lack of data and outdated information make it difficult to compare different regions and types of products. Anyway, Parfitt et al. [2] highlight how important it is to draw a distinction between losses of perishable food items from those of non-perishable items, as they have very different characteristics and causes.

In the case of non-perishable foods, such as corn, wheat, rice and soybeans, for example, losses in developed countries are significantly lower (between $0.07 \%$ and $2.81 \%$ ) than those recorded in developing countries [3]. It is suggested that because much of the grain production ends up being stored, many studies should focus on losses during this stage of the supply chain. This is the case, for example, of a study which modeled losses caused by Sitophilus zeamais and Rhyzopertha dominica in stored wheat [4]. However, 
even in these cases, it is very difficult to measure particularly qualitative losses.

A study published by Gustavsson et al. [5] estimates food loss patterns along the production and consumption chain worldwide for various groups of products. Table 1 shows food losses along the main stages of the production and distribution chain.

According to Chitarra and Chitarra [6], postharvest losses of more durable products, such as grains and cereals, are estimated to range from $5 \%$ to $30 \%$ in Brazil. In fact, a survey points out that postharvest rice losses range from $1 \%$ to $30 \%$ [2].

For fruits and vegetables, several studies have been carried out considering different stages of the production and distribution chain. Physical losses of bananas and tomatoes, for example, account for about $40 \%$ of their production, while those of oranges, grapes, mangoes and cucumbers amount to $22 \%-28 \%$ of their production [7]. A more recent study points to losses of about of $17.7 \%$ in the tomato production chain, $21 \%$ in the lady's finger banana production chain and $31.3 \%$ in the dwarf banana production chain [8].

In the case of tomatoes, it is estimated that losses in the tomato supply chain in California between the field and industrial processing facilities can be as high as $12 \%$ and are caused by excessive physical impacts along the way [9]. The authors also states that harvesting tomatoes during the hottest part of the day causes higher losses during transportation to processing facilities as compared to when they are reaped early in the morning. Losses during transportation amount to $2 \%-3 \%$ when tomatoes are harvested for processing at the right point of maturation, on the other hand, losses during transportation may be as high as $5 \%$ if they are harvested too ripe [10].

Fruit losses in the retail market are estimated to range between $3.2 \%$ and $15 \%$ in this stage, depending on the type of fruit and marketing site [11-13].

Thus, benefits in terms of food security in agribusiness may be derived not only from an increase in production, but also from avoiding losses along the supply chain. More specifically, improved roads, greater availability of alternative means of transportation or even an appropriate storage infrastructure, for example, can minimize possible losses along that chain and reduce the costs for transporting products. The results will be positive for farmers, for all the agents involved in transportation operations and ultimately for consumers.

Related to the relevance of the issue discussed, this paper aimed to characterize and measure physical losses along the wheat supply chain in Rio Grande do Sul (RS), Brazil, which accounts for almost half of the domestic wheat production. Besides the important role played by RS in wheat production, this production is characterized by many small farms and a great presence of cooperatives in the logistics chain. Based on the results obtained in this study, strategies are suggested to reduce food losses in different links of the logistics chain.

Table 1 Estimated losses (in \%) for groups of products by stage of the production chain in Latin America in 2011.

\begin{tabular}{llllll}
\hline Groups of products & $\begin{array}{l}\text { Agricultural } \\
\text { production }\end{array}$ & $\begin{array}{l}\text { Handling and } \\
\text { storage }\end{array}$ & $\begin{array}{l}\text { Processing and } \\
\text { packaging }\end{array}$ & Distribution & $\begin{array}{l}\text { Domestic } \\
\text { consumption }\end{array}$ \\
\hline Grains & 6.0 & 4.0 & $2.0-7.0$ & 4.0 & 10.0 \\
Roots and tubers & 14.0 & 14.0 & 12.0 & 3.0 & 4.0 \\
Oilseeds and legumes & 6.0 & 3.0 & 8.0 & 2.0 & 2.0 \\
Fruits and vegetables & 20.0 & 10.0 & 20.0 & 12.0 & 10.0 \\
Meat & 5.3 & 1.1 & 5.0 & 5.0 & 6.0 \\
Fish and seafood & 5.7 & 5.0 & 9.0 & 10.0 & 4.0 \\
Milk & 3.5 & 6.0 & 2.0 & 8.0 & 4.0 \\
\hline
\end{tabular}

Source: Ref. [5]. 


\section{Materials and Methods}

The study was divided into two points. In the first point, an extensive literature review was undertaken, mainly aiming at characterizing the wheat chain in RS. This first point was important to identify and define the agents to be interviewed in the second stage of the study. At the second stage, a primary data collection was conducted with the main agents of the production chain at RS.

Two types of questionnaires were drawn up with the aim of deepening and making better use of the survey based on the characteristics of the respondents: (1) a questionnaire for cooperatives and mills and (2) a questionnaire for transportation companies. These questionnaires aim understanding all the logistic chain's transactions between the agents in the market, quantifying the amount of physical losses in each logistic step and identifying how the actors are dealing with this issue.

The sample used in this study was not a probabilistic sample, meaning that it was defined beforehand due to the importance and representativeness of the agents involved in the wheat chain in the state of RS. This type of sample is referred to as "convenience sampling".

Thirteen agents operating in the wheat grain supply chain in the state of RS were interviewed, including the leaders of five cargo trucking companies, three flour mills, two cooperatives, two port terminals/traders and one farmers union. During the field survey, six municipalities in the state of RS were visited, involving distances of almost 590 miles.

\section{Results and Discussion}

The study focused on measuring the losses in the wheat supply chain in RS, and the interviews played a major role in ensuring that this objective was achieved.

The results achieved are presented in three parts. The first one provides a characterization of the supply chain in RS, mainly describing the role played by the agents involved in it, the main flows of the product, modes of transportation and types of vehicles being used. The second part presents the results for current losses in each link of the chain. Finally, the third part suggests strategies for reducing losses in the wheat supply chain.

\subsection{Characterization of the Wheat Supply Chain in RS}

This section presents the main results of the field survey, focusing on the wheat supply chain. For this purpose, it describes the role of agents involved in the wheat supply chain, the main flows of the product, modes of transportation and types of vehicles being used. In this study, the approach for estimating the effects of losses focused on the wheat flows is highlighted in Fig. 1.

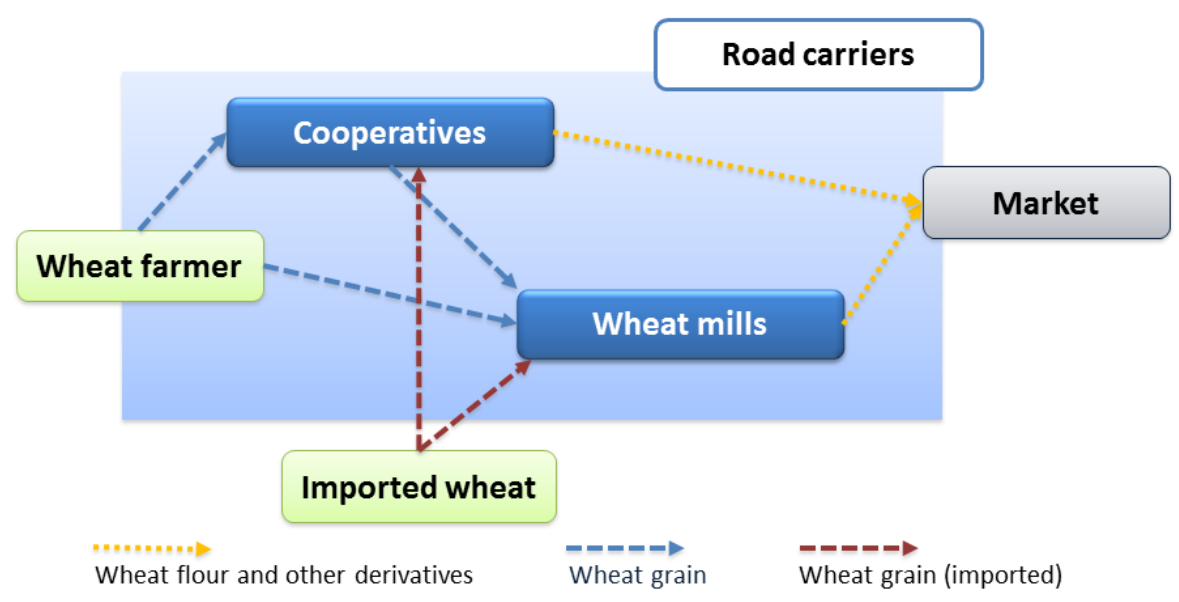

Fig. 1 Main wheat transportation flows. 
A first and important flow concerns wheat grains that leave production units and reach cooperatives. According to the Brazilian Institute for Geography and Statistics (IBGE) [14], there are 441,472 agricultural production units in RS, covering 20 million hectares. These units are predominantly composed of small farms, over $87 \%$ of which are less than 50 hectares in size. In particular, wheat production is mainly scattered throughout the state, but it is more concentrated in its northwest region. According to the National Supply Company (CONAB) [15], the state produced 1.9 million tons of wheat in the 2012-2013 harvest, accounting for about $43 \%$ of the national production (Table 2).

The flow between farmers and cooperatives became quite evident in the field survey, given the high volume involved. Farmers very often sell their production to cooperatives located near their farms, thus characterizing its transportation over relatively short distances and involving significant volumes of the product. The average distance traveled by vehicles loaded with wheat from the producing farms and cooperatives is usually short (between $20 \mathrm{~km}$ and 25 $\mathrm{km})$. In these cases, farmers are often the ones who take care of transporting their wheat to the cooperatives. Cooperatives then end up selling part of it to mills.

A second flow from the producing farms goes to mills. This is a less frequent transaction that only takes place when larger farmers are involved, who have the means to store and standardize the product. In the mills, the wheat grains are processed into flour and bran. Wheat flour is intended for preparing products for human consumption. Large mills often have their own product lines for sale, such as pasta and biscuits, and they also produce mixes for baking to be used by other processors, such as bakeries. Wheat bran is in turn intended for animal feed and is seen as a by-product of flour production, due to its lower value added. During this processing stage, imported wheat grains are mixed with domestic wheat. Imported wheat is usually more resistant to fermentation temperatures, is more concentrated in proteins, and is seen as a higher quality product due to its greater size and weight.

In these two wheat grain transportation flows from production units, the wheat is exclusively transported by road. Particularly for transportation operations, vehicles owned by the farmers themselves are often used and carriers are only hired when there is a surplus volume or when farmers do not have a fleet of their own. When the third parties are hired to transport the product, reputation and trust are important factors in determining the decision to hire them, given that the drivers are from the same region where the farm and the cooperative are located. It should be noted that the vehicles are not weighed on the farms. That is, they are loaded to the limit of their capacity and are instructed to unload their cargo at cooperatives or mills. Therefore, losses during transportation along this path, albeit small, are not accounted for.

At the cooperative, wheat can be processed or alternatively sold to a mill or trader (in the latter case, for export purposes). Processing by the cooperative itself is a market practice, but the wheat is usually sold to mills, which process the grains and sell the resulting wheat flour and other derivatives, as mentioned above.

In fact, the wheat taken to mills comes mainly from cooperatives. Moreover, as mentioned above, part of the wheat is imported, since there is a great need for "improved wheat," and the rest ends up being bought

Table 2 Area, production and productivity of wheat in the state of RS, in 2012-2013 harvest.

\begin{tabular}{|c|c|c|c|c|c|}
\hline \multicolumn{2}{|c|}{ Area } & \multicolumn{2}{|c|}{ Production } & \multicolumn{2}{|c|}{ Productivity } \\
\hline $\mathrm{RS}$ & $\%$ in Brazil & $\mathrm{RS}$ & $\%$ in Brazil & $\mathrm{RS}$ & Brazil \\
\hline $\begin{array}{l}976 \text { thousand } \\
\text { hectares }\end{array}$ & $51.5 \%$ & $\begin{array}{l}\text { 1.894 thousand } \\
\text { tons }\end{array}$ & $43.3 \%$ & $1.941 \mathrm{~kg} / \mathrm{ha}$ & $2.311 \mathrm{~kg} / \mathrm{ha}$ \\
\hline
\end{tabular}

Source: CONAB [15]. 
from large local farmers provided with a storage infrastructure.

Because of their capacity to standardize wheat in terms of moisture and impurities, for example, cooperatives play a major role in supplying wheat to mills. Again, the wheat is mainly transported by road and the mills are usually the ones responsible for transporting it. In this case, the mills use their own fleets for transporting it and carriers are hired to transport surplus volumes. Much importance is given to the quality of the wheat taken to mills, and impurity, moisture and hectoliter weight standards, for example, need to be met, so that the limits prescribed in the contract between the two agents are not exceeded. If differences are found between contract clauses and the product sent to a mill, it is not accepted by the latter and it is sent back to the cooperative, which has to bear the transportation costs.

Due to the need to use improved wheat, the mills mix the imported and domestic wheat. Argentina, Uruguay, Paraguay, the United States and Canada are the main countries of origin of the wheat imported by Brazil. In practice, the need for this product is determined by clients, who pay a higher price for better quality flour. In this case, the mills buy foreign wheat from an intermediary, usually a trader, which transports the wheat to Brazil. Imported wheat is transported to RS through waterways and it enters the country mainly through the Rio Grande Port. The Patos Lagoon plays an important role in waterborne transportation of the product to the interior of the state, especially in the region of Porto Alegre, from where the wheat is transported to mills by truck (with the mills using their own fleet or hiring a carrier to do that). Thus, multimodal transportation is often used to transport imported wheat to cooperatives or mills. Once the imported wheat arrives at the mill, its mixing with domestic wheat and processing are carried out according to specific requests from the mill customers. After it is processed, the resulting wheat flour and other end products are sold to meet the demand of the market (wholesale and retail market). It is not a common practice to transport wheat flour in bulk in trucks, and it is more often transported in sacks.

\subsection{Losses in the Wheat Supply Chain}

Wheat grain losses were quantified during the following stages of its supply chain: harvesting (on farms), storage (in cooperatives), processing (in wheat mills) and transportation (from farms to cooperatives, and from cooperatives to wheat mills). Other flows were not considered in this analysis of losses.

About 6\% are the estimated losses on the farms during harvesting. Factors leading to such losses include the use of inadequate implements and inadequately adjusted machinery in harvesting operations and the speed at which they are carried out. Adverse weather and soil conditions also end up contributing to this result.

Losses during wheat grain transportation from farms to cooperatives (referred to here as T1) are in turn estimated to account for about $0.5 \%$ of all the wheat loaded into trucks. It should be mentioned that it is difficult to measure these losses and that such measurement involves a certain degree of uncertainty, since the vehicles are not weighed on the farms. Respondents stated that losses during transportation do occur but are not actually accounted for, and that the only reason they are not greater is because the distances between the source (production units) and destination (cooperatives) are small. The main factors that determine losses during transportation are related to the payload capacity of the vehicles (which is usually exceeded) and poor road conditions (usually dirt roads).

At the cooperatives, the wheat is stored and standardized before being sold to mills. In this process of storing and transporting wheat to mills, the infrastructure conditions prevailing in the cooperatives are far from ideal, and even when quality controls are applied, they are not sufficient to bring loss levels down. Furthermore, attacks by pests and rodents 
contribute to losses in this stage. As a result, losses during storage amount to $5 \%$ of the total volume that is taken to the cooperatives, as was seen based on the interviews that were held. It should be noted that the interviews clearly showed that losses during storage vary among different regions. Therefore, one should be cautious in extrapolating this percentage to other regions.

During the transportation of wheat from cooperatives to mills (T2), the existence of weighing structures at both ends allows for a more effective control of losses. In this case, the maximum tolerance is a loss of $0.2 \%$ of the weight carried on the vehicle. After this limit, carriers must bear the cost of the difference. In practice, losses usually exceed this limit by a small margin. Based on the results of the field survey, it was seen that they amount to $0.3 \%$ on average. Anyway, these losses are lower than in the first transportation stage (between farms and cooperatives), due to the fact that in this case, roads are mostly paved and loading operations at the cooperatives are more technological and efficient than on the farms.

Finally, respondents reported that no significant losses occur during the wheat industrialization process in mills, mainly due to the addition of water during the grinding process. Fig. 2 summarizes the results for losses in each link of the wheat supply chain in RS.

Total losses during transportation between farms and mills account for $11.8 \%$ of all transported wheat grains. Losses during harvest and storage in cooperatives, which account for $93.2 \%$ of total losses, stand out in this context. Transportation operations (T1 and $\mathrm{T} 2$ ) account for $6.8 \%$ of total losses in this flow.

Considering that mills in RS processed 1.68 million tons of wheat in 2013 [16], these losses account for about 200,000 tons per year. This means that a volume that would be sufficient to feed nearly 3,000 people is lost. It is as if about 6,700 trucks loaded with wheat never reached their final destination. Losses during transshipment operations of imported wheat and during subsequent wheat processing stages in mills must be added to these figures.

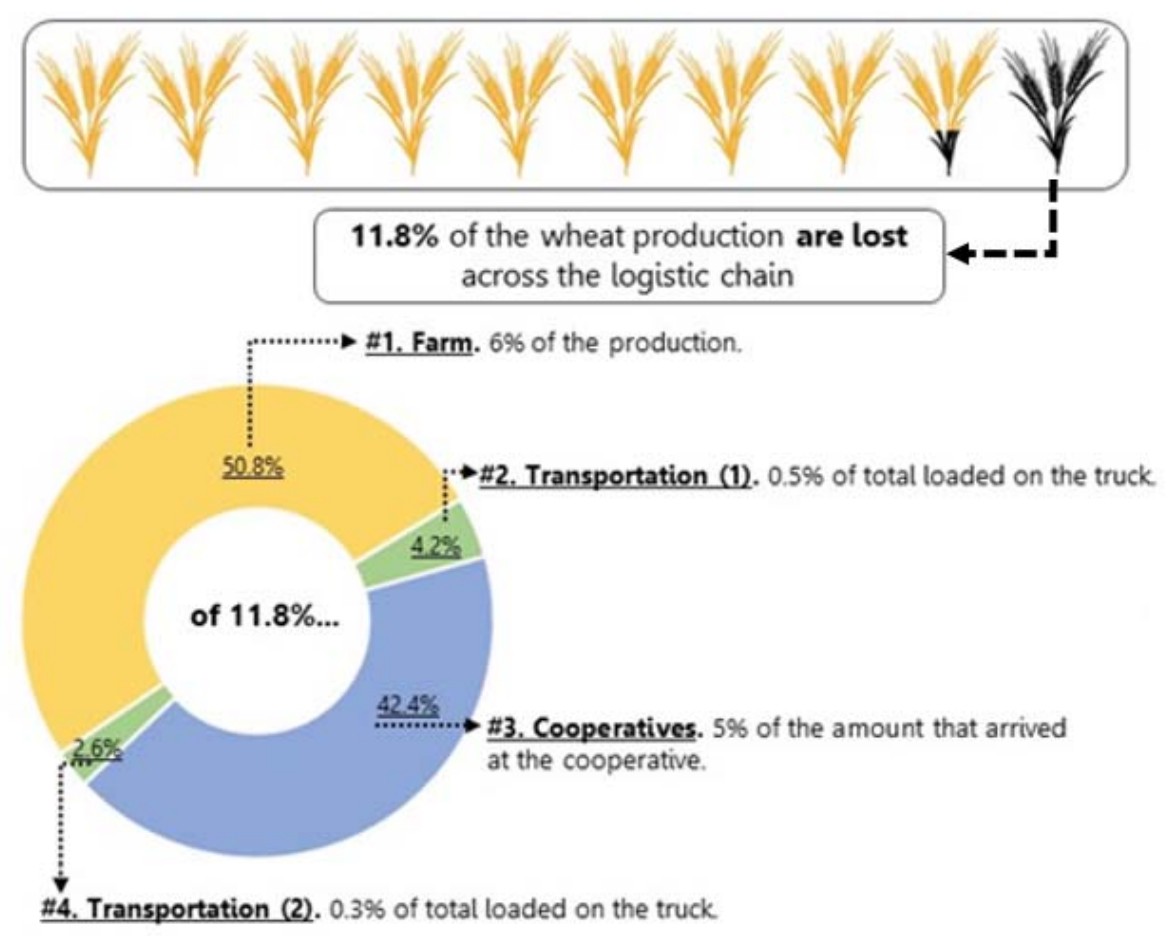

Fig. 2 Estimated losses in the wheat supply chain.

Source: prepared by the authors based on the results of the survey. 
It is also important to point out that, throughout the supply chain, losses are not seen as a problem to be solved. They are seen as only natural in the process of buying, selling and transporting the product, and few players in this market are concerned about reducing loss levels. This is so because these numbers, when known, are seen in isolation and not as figures that are linked to one another as in a supply chain. This position of the agents in relation to measuring losses also prevails in other agro-industrial chains in Brazil.

When they are converted into monetary units, these losses are not negligible and highlight the need for searching for alternatives to minimize them in each stage of the supply chain. In addition, loss reductions also increase the availability of food (contributing to increasing food security and reducing local rural poverty levels) and reduce pressures on the environment.

\subsection{Strategies to Reduce Losses in the Wheat Supply Chain}

Possible strategies to reduce postharvest losses include those that can be adopted by agents involved in the supply chain and others that depend on more direct government interventions in the form of public policies. Some of the key measures that could be taken based on the results of the study will be suggested and discussed below. These measures are not exhaustive, but they stand out as the most obvious and important ones in terms of the impacts they could have on reducing losses.

First, put in evidence the issue of wheat losses to the agent involved in its supply chain. The straight monetary impact of the losses on the farmer and cooperative's revenue stands out the need of avoiding this kind of problem. Pointing out the dimension which this event can reach is the first step for the loss reduction.

Second, manage losses and set reduction targets. Measuring losses periodically constitutes a first step toward minimizing them. The study shows that most agents involved in this agro industrial chain (as in others) have not been investing in measuring, monitoring and managing losses. With a management system in place, even a simple one, baselines can be set to identify the most critical stages and set loss reduction targets along the supply chain.

Third, give attention to transportation service levels. The quality of transportation services in terms of both the type of vehicles used and their loading characteristics (such as remaining within the payload capacity of the vehicles) can provide major contributions to reducing losses. The revenues resulting from such reduction can more than offset higher freight costs due to a differentiated service level in the case of hired carriers. On the other hand, these revenues can be used to buy newer and more efficient vehicles for fleets owned by the farmers or cooperatives themselves.

Lastly, more public and private investments are given in storage infrastructure and transportation infrastructure:

(1) Storage infrastructure: Lack of adequate storage infrastructure is the primary source of losses. Technologies that ensure storage in airtight conditions protect the grain from moisture and pests. Besides avoiding losses, storage under these conditions allows for farmers to wait for the best moment to sell the grain, thus ensuring higher revenues.

(2) Transportation infrastructure: A better transportation infrastructure can go a long way to reducing loss levels. In this context, the importance of highways in good conditions and the availability of alternative modes of transportation stand out.

\section{Conclusions}

This study characterized the wheat supply chain in the state of RS and measured losses in the flow between farmers and mills. The study showed that $11.8 \%$ of the wheat is lost during the logistical stages analyzed here, which is equivalent to about 200,000 tons/year. Postharvest losses on the farms are about 
$6 \%$ and during the storage in cooperatives are approximately 5\%. Losses during transportation can amount to $0.8 \%$, of which about $0.5 \%$ are losses during $\mathrm{T} 1$ stage and about $0.3 \%$ occur during $\mathrm{T} 2$ stage. Basically, the transportation conditions prevailing in these two segments (both in terms of vehicles and the conditions of the roads involved) explain the different losses rates found in $\mathrm{T} 1$ and $\mathrm{T} 2$.

It was also observed that losses have very different meanings for the agents involved in the wheat supply chain in RS. In general, farmers are not concerned about losses. Since the trucks are not weighed on the farms, farmers frequently have no reference about losses between their farms and cooperatives or mills. For this reason, it is a common practice to overload vehicles, still increasing the probability of losses rates. On the other hand, losses become an important issue in the flows between cooperative and mills. Quantitative losses should be measured, as well as mean monetary losses.

Finally, based on the results of the study, some suggestions to reduce losses are related to public policies, such as improvements of the transport and warehouse infrastructures, and the strategic management of the wheat supply chain, by measuring losses rates and setting reduction targets.

\section{References}

[1] Lipinski, B., Hanson, C., Lomax, J., Kitinoja, L., Waite, R., and Searchinger, T. 2013. "Reducing Food Loss and Waste.” World Resources Institute (WRI). Accessed June, 2013. http://www.wri.org/publication/reducing-food-lossand-waste.

[2] Parfitt, J., Barthel, M., and Macnaughton, S. 2010. "Food Waste within Food Supply Chains: Quantification and Potential for Change to 2050.” Phil. Trans. Roy. Soc. 365 (1554): 3065-81.

[3] Smil, V. 2004. "Improving Efficiency and Reducing Waste in Our Food System.” J. Environ. Sci. 1 (1): 17-26.

[4] Silva, A. A. L., Faroni, L. R., Guedes, R. N. C., Martins, J. H., and Pimentel, M. A. G. 2003. "Mathematical
Modeling of the Losses Caused by Sitophilus zeamais and Rhyzopertha dominica in Stored Wheat." Revista Brasileira de Engenharia Agrícola e Ambiental 7 (2): 292-6. (in Portuguese)

[5] Gustavsson, J., Cederberg, C., and Sonesson, U. 2011. Global Food Losses and Food Waste. Roma: FAO.

[6] Chitarra, M. I. F., and Chitarra, A. B. 2005. Postharvesting of Fruits and Vegetables: Physiology and Handling. Lavras: Ufla.

[7] Caixeta-Filho, J. V. 1999. "Losses in the Transportation of Fruit and Vegetables: A Brazilian Case Study.” Int. J. Logist. Res. Appl. 2 (3): 325-41.

[8] Almeida, G. S., and Silva, T. 2008. Evaluation of Losses in the Commercial Chain of Banana Nanica, Banana Prata and Tomato Longa Vida. Technical Study Report, Centrais de Abastecimento de Minas Gerais SA (CEASAMINAS), Belo Horizonte.

[9] Gameiro, A. H., Caixeta-Filho, J. V., Rocco, C. D., and Rangel, R. 2008. "Modeling and Management of Losses in the Supply of Tomatoes for Manufacturing Process.” Gestão e Produção 15 (1): 101-15. (in Portuguese)

[10] Moretti, C. L., Calbo, A. G., and Henz, G. P. "Physiology and Postharvest Management.” In Tomato to Industrial Processing, edited by Silva, J. B. C., and Giordano, L. B. Brasilia: EMBRAPA Comunicação para Transferência de Tecnologia (EMBRAPA-CNPH), 136-43. (in Portuguese)

[11] Silva, C. S., Perosa, J. M. Y., Rua, P. S., Abreu, C. L. M., Pântano, S. C., Vieira, C. R. Y. I., and Brizola, R. M. O. 2003. "Economic Evaluation of Banana Losses in the Retail Market: A Case Study.” Revista Brasileira de Fruticultura 25 (2): 229-34. (in Portuguese)

[12] Perosa, J. M. Y., and Silva, C. S. 2009. "Evaluation of Mango Losses in the Retail Market in Botucatu.” Revista Brasileira de Fruticultura 31 (3): 732-8. (in Portuguese)

[13] Tofanelli, M. B. D., Fernandes, M. S., Martins Filho, O. B., and Carrijo, N. S. 2007. "Loss of Fresh Fruit at Retail in Mineiros-GO: A Study Case.” Revista Brasileira de Fruticultura 29 (3): 513-7. (in Portuguese)

[14] Brazilian Institute for Geography and Statistics (IBGE). 2006. “Agricultural Census.” Accessed July 12, 2016. http://www.ibge.gov.br/home/estatistica/economia/agrope cuaria/censoagro/2006. (in Portuguese)

[15] National Supply Company (CONAB). 2014. "Historical Series.” Accessed July 12, 2016. http://www.conab.gov.br. (in Portuguese)

[16] Abitrigo. 2013. “Statistics.” Accessed July 12, 2016. http://www.abitrigo.com.br. (in Portuguese) 


\section{Appendix}

Table 1 Questionnaire script.

1. Cooperatives/mills

Inbound transportation:

Who is the agent responsible for the wheat transportation? Who is hiring this operation (farmers or the company)?

Where does the wheat come from (most common origin)?

In which moment (and places) are the trucks weighed?

Which is the most common type of truck?

Does the company use railway and waterway for the wheat transportation?

How much wheat is lost during the transport (for each transportation modal)?

Processes:

Is the cooperative/mill responsible for the whole industrial process?

Describe the industrial process.

Which are the final products?

How much wheat is lost during the industrial phases (\%)?

Storage:

Who is the owner of the warehouse infrastructure?

What is the most common type of warehouse infrastructure?

How much wheat is lost during the storage phase?

2. Trucking companies

Wheat transportation:

Describe the transportation market (agents, contracts, etc.).

Is the "spot market" representative? How much?

Is there any weight control for the trucks when they leave the farm? Describe the weight control.

What is the average distance between the farm and the cooperative/mill?

How do you measure the losses during the transport operation?

How much wheat is lost during the transport operation (\% or $\mathrm{kg}$ )? Is there any contractual limit? Who is the agent responsible for the payment of the amount lost during the transport operation?

Is there any difference in the weighing rules for export and import flows?

Good practices:

What about the quality of the trucks? Do the trucks have good conditions for each transport operation? What is the trucking average age?

Does the trucking company work with own vehicles or third parties?

Does the amount lost vary as function of the type of truck and of the conditions of the road?

Is there any kind of training that focuses in loss reduction during the transport operation (good practices)? 